\title{
5-Hydroxymethyl-Furfural and Structurally Related Compounds Block the lon Conductance in Human Aquaporin-1 Channels and Slow Cancer Cell Migration and Invasion
}

\author{
Pak Hin Chow, Mohamad Kourghi, Jinxin V. Pei, Saeed Nourmohammadi, \\ and Andrea J. Yool \\ Adelaide Medical School, University of Adelaide, Adelaide, Australia (P.H.C., M.K., J.V.P., S.N., A.J.Y.) and College of Science, \\ The Australian National University, Canberra, Australia (J.V.P.)
}

Received December 18, 2019; accepted April 20, 2020

\begin{abstract}
Aquaporin-1 (AQP1) dual water and ion channels enhance migration and invasion when upregulated in leading edges of certain classes of cancer cells. Work here identifies structurally related furan compounds as novel inhibitors of AQP1 ion channels. 5-Hydroxymethyl-2-furfural (5HMF), a component of natural medicinal honeys, and three structurally related compounds, 5-nitro-2-furoic acid (5NFA), 5-acetoxymethyl-2-furaldehyde (5AMF), and methyl-5-nitro-2-furoate (M5NF), were analyzed for effects on water and ion channel activities of human AQP1 channels expressed in Xenopus oocytes. Two-electrode voltage clamp showed dose-dependent block of the AQP1 ion current by $5 \mathrm{HMF}\left(\mathrm{IC}_{50} 0.43 \mathrm{mM}\right), 5 \mathrm{NFA}\left(\mathrm{IC}_{50} 1.2 \mathrm{mM}\right)$, and 5AMF $\left(\mathrm{IC}_{50} \sim 3 \mathrm{mM}\right)$ but no inhibition by M5NF. In silico docking predicted the active ligands interacted with glycine 165, located in loop D gating domains surrounding the intracellular vestibule of the tetrameric central pore. Water fluxes through separate intrasubunit pores were unaltered by the furan compounds (at concentrations up to $5 \mathrm{mM}$ ). Effects on cell migration, invasion, and cytoskeletal organization in vitro were tested in high-AQP1-expressing cancer lines, colon cancer (HT29) and AQP1-expressing breast cancer (MDA),
\end{abstract}

and low-AQP1-expressing SW480. 5HMF, 5NFA, and 5AMF selectively impaired cell motility in the AQP1-enriched cell lines. In contrast, M5NF immobilized all the cancer lines by disrupting actin cytoskeleton. No reduction in cell viability was observed at doses that were effective in blocking motility. These results define furans as a new class of AQP1 ion channel inhibitors for basic research and potential lead compounds for development of therapeutic agents targeting aquaporin channel activity.

\section{SIGNIFICANCE STATEMENT}

5-Hydroxymethyl-2-furfural (5HMF), a component of natural medicinal honeys, blocks the ion conductance but not the water flux through human Aquaporin-1 (AQP1) channels and impairs AQP1-dependent cell migration and invasiveness in cancer cell lines. Analyses of $5 \mathrm{HMT}$ and structural analogs demonstrate a structure-activity relationship for furan compounds, supported by in silico docking modeling. This work identifies new low-cost pharmacological antagonists for AQP1 available to researchers internationally. Furans merit consideration as a new class of therapeutic agents for controlling cancer metastasis.

\section{Introduction}

Aquaporin (AQP) channels, found in all kingdoms of life, serve essential roles in transmembrane fluid and solute fluxes, enabling regulation of volume and osmotic gradients across cell membranes (Agre et al., 1993; Reizer et al., 1993; Hohmann et al., 2000; Gomes et al., 2009). AQP channels are tetramers of subunits with monomeric pores that facilitate osmotic water flux (Jung et al., 1994; Sui et al., 2001). In AQP1, the central pore is a cGMP-gated nonselective cation channel, permeable to monovalent cations such as $\mathrm{Na}^{+}, \mathrm{K}^{+}$,

Primary laboratory of origin: (AJ Yool; Aquaporin Physiology and Drug Discovery Program, Adelaide Medical School, University of Adelaide, Adelaide, Australia).

This work was supported by the Australian Research Council [Grants 16ARC DP16010464 and 19ARC DP190101745].

https://doi.org/10.1124/mol.119.119172.
$\mathrm{Cs}^{+}$, and $\mathrm{Li}^{+}$, and pharmacologically distinct from the intrasubunit water pores (Yool et al., 1996; Saparov et al., 2001; Boassa and Yool, 2003; Yu et al., 2006; Campbell et al., 2012; Kourghi et al., 2018; Pei et al., 2019). Ion channel activity has been reported for other AQPs expressed in mammals (AQP0, AQP6), as well as in insects (Drosophila Big Brain) and plants (soybean nodulin 26 and rockcress AtPIP2; 1) (Weaver et al., 1994; Anthony et al., 2000; Hazama et al., 2002; Yanochko and Yool, 2002; Boassa et al., 2006; Byrt et al., 2017).

Chemical modulators of AQP water and glycerol channel activities have been characterized by research teams around the world (Yool et al., 2010; Huber et al., 2012; Martins et al., 2013; Seeliger et al., 2013; Pei et al., 2016a). Inhibitors of the human AQP1 ion conductance identified thus far include bacopaside I from the Ayurvedic medicinal plant Bacopa monnieri and derivatives of bumetanide, AqB007 and AqB011,

ABBREVIATIONS: 5AMF, 5-acetoxymethyl-2-furaldehyde; AQP, aquaporin; 8CPT-cGMP, 8-(4-chlorophenylthio)-guanosine 3',5'-cyclic monophosphate; DMEM, Dulbecco's modified Eagle's medium; 5HMF, 5-hydroxymethyl-2-furfural; MDA, MDA-MB-231; M5NF, methyl-5-nitro-2furoate; 5NFA, 5-nitro-2-furoic acid; PCR, polymerase chain reaction; RPS13, ribosomal protein S13. 
which also act to slow cell migration and decrease invasiveness in classes of cancer cell lines that express high levels of AQP1 (Kourghi et al., 2016; Pei et al., 2016b). Divalent cations, such as $\mathrm{Cd}^{2+}$ and $\mathrm{Ca}^{2+}$, also inhibit $\mathrm{AQP} 1$ ion conductance (Boassa et al., 2006; Kourghi et al., 2017). The ongoing search for modulators is important for developing a pharmacological armamentarium for AQP research, for identifying drug candidates aimed at potential future clinical translations, and for building understanding of ligand structure-activity relationships for diverse classes of AQPs.

Traditional medicines have been used by humans for more than 4000 years as valuable mixtures of agents with likely therapeutic effects, including anticancer activities (Khan, 2014; He et al., 2019). Natural remedies based on manuka and tualang honeys are reported to have antioxidant (Khalil et al., 2012), anti-inflammatory (Gasparrini et al., 2018), antibacterial (Girma et al., 2019), and antidiabetic (Lori et al., 2019) effects, with benefits in gastrointestinal disorders (Ghosh and Playford, 2003), wound infections (Shan, 2019), and cancers (Attia et al., 2008; Aryappalli et al., 2017; Abel et al., 2018; Afrin et al., 2018). Medicinal extracts have been useful as sources of new pharmacological agents to modulate proteins involved in diverse physiologic functions, including for example ion channels, receptors, and transporters (Sucher and Carles, 2015).

One of the compounds naturally occurring in both manuka and tualang honeys is 5-hydroxymethyl-2-furfural (5HMF), which shows differences in concentration levels that have been suggested to correlate with therapeutic effectiveness (Ahmed and Othman, 2013). 5HMF confers protective effects in brain and cardiac ischemic injury models. Intraperitoneally injected $5 \mathrm{HMF}(12 \mathrm{mg} / \mathrm{kg})$ reduced neurologic deficits and brain edema in mice after transient global cerebral ischemia (Ya et al., 2017). In perfused isolated rat hearts, $5 \mathrm{mM} 5 \mathrm{HMF}$ reduced damage during 20-minute no-flow ischemia, enhanced coronary artery relaxation, and accelerated recovery to normal sinus rhythm during reperfusion (Wölkartet al., 2017).

Work here tested for effects of 5HMF and related compounds on the ion conductance and the water channel activity of human AQP1 channels expressed in Xenopus oocytes and evaluated the effects of the same agents on the rates of migration and invasiveness of AQP1-expressing breast cancer (MDA) and colon cancer (HT29) cell lines and a colon cancer line with low levels of AQP1 (SW480). Results showed that $5 \mathrm{HMF}$ blocked the ion conductance but not the osmotic water flux mediated by AQP1, and provided evidence for a structureactivity relationship for furan compounds, which was supported by results from in silico docking modeling. Block of cell migration in AQP1-positive lines correlated with effectiveness in inhibiting AQP1 for three (5HMF, 5ANF, 5NFA) of the four agents tested. The fourth compound, M5NF, blocked motility in all cell lines by an AQP1-independent mechanism. These results expand the panel of known AQP1 modulatory agents and identify new low-cost pharmacological antagonists that are available from commercial suppliers internationally. Possible therapeutic activities of improved furan derivatives in animal models of cancer metastasis could be of interest in future research.

\section{Materials and Methods}

Oocyte Preparation and cRNA Injection. Unfertilized oocytes were harvested from anesthetized female Xenopus laevis frogs in

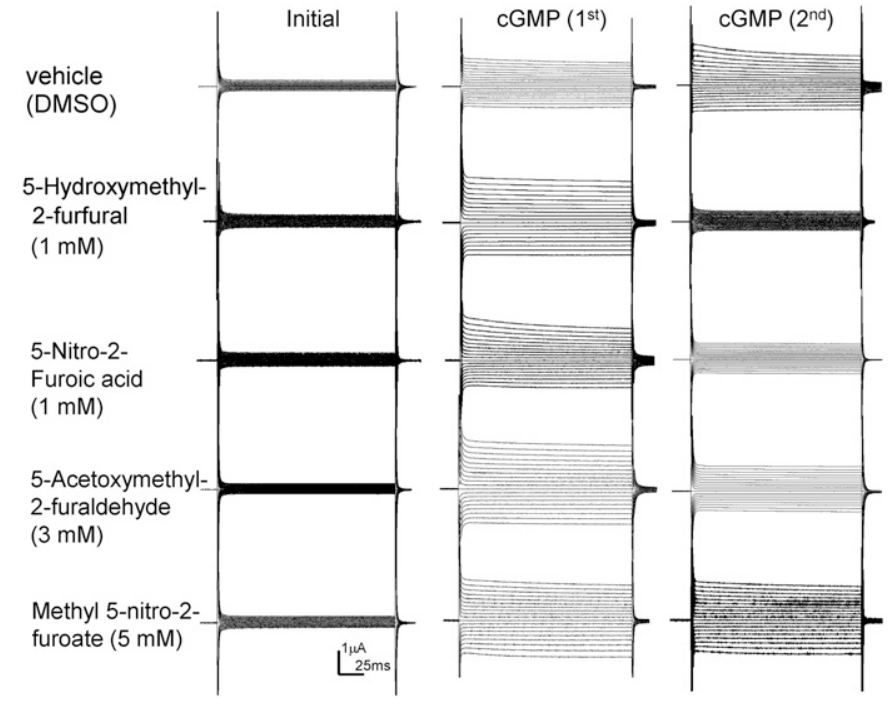

Fig. 1. Electrophysiological recordings illustrating the effects of $5 \mathrm{HMF}$ and related compounds on the cGMP-activated AQP1 ion conductance. 5Hydroxymethyl-2-furfural, 5-nitro-2-furoic acid, 5-acetoxymethyl-2-furaldehyde, and methyl 5-nitro-2-furoate were tested for effects on the ionic conductance of AQP1-expressing oocytes. Each row shows responses recorded during the sequential treatment of a single oocyte: first, prior to application of 8CPT-cGMP (initial; left); second, at 30 minutes after the first application of 8CPT-cGMP (cGMP first; middle); and third, after 2 hours incubation in the indicated treatment followed by 30 minutes reapplication of $8 \mathrm{CPT}$-cGMP (cGMP second; right).

accordance with national guidelines (Australian Code of Practice for the Care and Use of Animals for Scientific Purposes), using protocols approved by the University of Adelaide Animal Ethics Committee (M2018-016). Harvested oocytes were defolliculated in collagenase type $1 \mathrm{~A}(2 \mathrm{mg} / \mathrm{ml})$ in isotonic saline $(100 \mathrm{mM} \mathrm{NaCl}, 2 \mathrm{mM} \mathrm{KCl}, 5 \mathrm{mM}$ $\mathrm{MgCl}_{2}$, and $5 \mathrm{mM}$ HEPES; $\mathrm{pH} 7.6$ ) for 1.5 hours at approximately $18^{\circ}$ C. Oocytes were washed three times with isotonic saline and transferred into frog Ringer's saline [isotonic saline supplemented with $0.6 \mathrm{mM} \mathrm{CaCl}_{2}, 5 \%$ horse serum (v/v), $100 \mathrm{U} / \mathrm{ml}$ penicillin, $0.1 \mathrm{mg} / \mathrm{ml}$ streptomycin, and $0.5 \mathrm{mg} / \mathrm{ml}$ tetracycline]. Healthy oocytes were injected with $50 \mathrm{nl}$ of sterile water (non-AQP1 control oocytes) or 50 nl wild-type human AQP1 cRNA (approximately $1 \mathrm{ng}$ in sterile water). Injected oocytes were incubated in frog Ringer's saline at $18^{\circ} \mathrm{C}$ for 48 hours or more to allow time for protein expression. Prior to experimental assays, control and AQP1-expressing oocytes were rinsed in isotonic saline (without serum, antibiotic free) for at least 1 hour.

Human AQP1 cDNA (National Center for Biotechnology Information GenBank NM_198098) (Preston et al., 1992) subcloned in a Xenopus $\beta$-globin expression plasmid was linearized with BamHI and transcribed using T3 polymerase (T3 mMessage mMachine; Ambion, Austin, TX). The cRNA was resuspended in sterile water and stored at $-80^{\circ} \mathrm{C}$. All chemicals are from Sigma-Aldrich Chemicals (St. Louis, MO) unless otherwise indicated.

Furan Compounds. $5 \mathrm{HMF}$ and three structurally related compounds: 5-nitro-2-furoic acid (5NFA); 5-acetoxymethyl-2-furaldehyde 9 (5AMF), and methyl 5-nitro-2-furoate (M5NF), were purchased from Sigma-Aldrich Chemicals. 5HMF was dissolved in water, whereas other compounds were dissolved in DMSO to create $1000 \times$ stock solutions, diluted $1 \mu \mathrm{l} / \mathrm{ml}$ into experimental salines to final concentrations. The equivalent amount of DMSO alone $(0.1 \%)$ in saline or cell culture medium was used as the vehicle control.

Quantitative Swelling Assay. For the swelling assays, each oocyte served as its own control, as described previously (Migliati et al., 2009). Each oocyte was tested first without drug treatment, incubated for 2 hours in isotonic saline with vehicle or with one of the furfural-related compounds, and then reassessed in a second swelling 
assay. Swelling rates were measured in $50 \%$ hypotonic saline (isotonic saline diluted with an equal volume of water, without test compounds present). Oocytes were imaged with a grayscale camera (Cohu, San Diego, CA) on a dissecting microscope (Olympus SZ-PT; Olympus, Macquarie Park, Australia) at one frame per second for 30 seconds using NIH ImageJ software. Oocytes were then incubated in isotonic saline alone, with vehicle, or with the indicated compound and were reassessed in a second swelling assay. The swelling rates were calculated from slope values of linear regression fits of crosssectional areas as a function of time using GraphPad Prism.

Electrophysiology. Two-electrode voltage-clamp recordings of control and AQP1-expressing oocytes in isotonic $\mathrm{Na}^{+}$saline were done with capillary glass electrodes (1-3 $\mathrm{M} \Omega$ ) filled with $1 \mathrm{M} \mathrm{KCl}$ using a GeneClamp amplifier. Bath application of membrane-permeable 8-(4-chlorophenylthio)-guanosine $3^{\prime}, 5^{\prime}$-cyclic monophosphate (8CPTcGMP) activated the ionic conductance in AQP1-expressing oocytes, as described previously (Campbell et al., 2012). The ionic conductance in AQP1-expressing oocytes was activated by application of a bolus of $8 \mathrm{CPT}-\mathrm{cGMP}$ to achieve a final bath concentration of $10 \mu \mathrm{M}$. Changes in current over time were monitored by brief repeated voltage step protocols to $+40 \mathrm{mV}$ from a holding potential of -40 every 6 seconds. Conductance values were measured using voltage steps from +60 to $-110 \mathrm{mV}$. Recordings were filtered at $2 \mathrm{kHz}$ and stored to hard disk for offline analysis. Data were analyzed with Clampex 9.0 software (pClamp 9.0; Molecular Devices, Sunnyvale, CA) and Prism software (GraphPad, San Diego, CA).

Molecular Modeling. In silico modeling was conducted as reported previously (Pei et al., 2016b). The protein crystal structures of human AQP1 were obtained from the Protein Data Bank (Protein Data Bank ID:1FQY). Structures for 5HMF and related compounds were downloaded from PubChem and converted into softwarecompatible three-dimensional structures in .pdb format using the online SMILES Translator and Structure File Generator (National Cancer Institute, U.S. Department Health and Human Services, Washington, DC). Both AQP1 and ligand coordinates were prepared for docking using MGLtools (version 1.5.4; Scripps Institute, San Diego, CA). The docking was carried using Autodock Vina (Trott and Olson, 2010), with a docking grid covering the intracellular face of the tetrameric pore.

Cancer Cell Culture and Migration Assays. HT29 and SW480 colon cancer cell lines and MDA-MB-231 (referred to here as "MDA") breast cancer cell lines (from American Type Culture Collection, Manassas, VA) were grown in Dulbecco's modified Eagle's medium (DMEM) supplemented with $1 \times$ glutaMAX (Life Technologies, Mulgrave, Australia), penicillin and streptomycin (100 U/ml each), and $10 \%$ FBS (v/v) at $37^{\circ} \mathrm{C}$ in a $5 \% \mathrm{CO}_{2}$ humidified environment. For wound healing assays of two-dimensional migration over flat surfaces, confluent cultures of cancer cell lines were tested using the circular wound closure method (De Ieso and Pei, 2018) to measure the effect of $5 \mathrm{HMF}$ and related compounds on the rates of cell migration. Cells were plated in flat-bottomed 96 well plates at $1.25 \times 10^{5}$ cells per well for HT29, or $1 \times 10^{5}$ cells per well for MDA and SW480 lines, in DMEM supplemented with $1 \times$ glutaMAX (Life Technologies), penicillin and streptomycin (100 U/ml each), and 10\% FBS. Cultures were incubated at $37^{\circ} \mathrm{C}$ in $5 \% \mathrm{CO}_{2}$ for $18-24$ hours. Once cells achieved $80 \%-$ $90 \%$ confluence, the culture medium was replaced with reduced serum (2\% FBS) DMEM medium with $400 \mathrm{nM}$ of the mitotic inhibitor 5fluoro-2'-deoxyuridine, and cells were incubated overnight to achieve a confluent monolayer. Circular wounds were created with a sterile p10 pipette tip; wells were washed two times with PBS to remove cell debris. Reduced serum DMEM culture medium (containing either vehicle or furan derivatives) was applied into the wells. Images of wounds were taken at 0 and 24 hours with a Canon 6D camera on an Olympus CK2 microscope $(10 \times$ objective). Wound areas were quantified using NIH ImageJ software (US National Institutes of Health) as described previously (De Ieso and Pei, 2018).

Transwell invasion assays were used to measure three-dimensional migration through an extracellular matrix. Cells were grown to

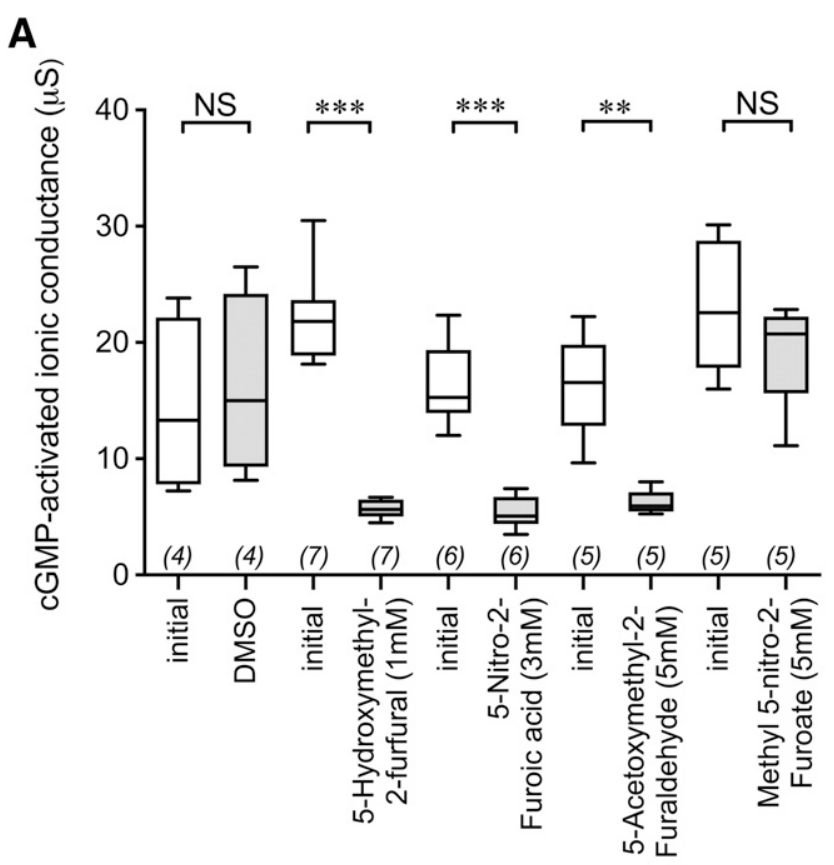

B

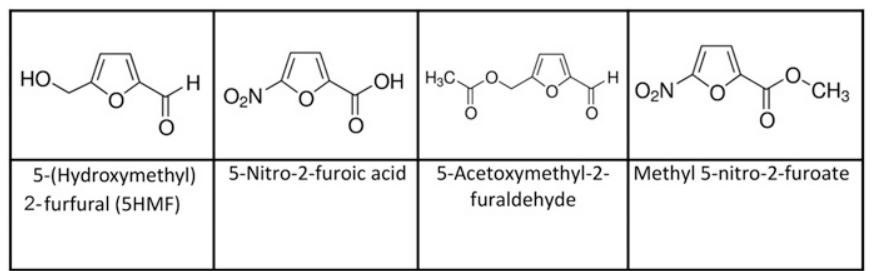

Fig. 2. Differential inhibition of the cGMP-activated AQP1 conductance by $5 \mathrm{HMF}$ and related compounds. (A) Box plot showing inhibition of the cGMP-activated AQP1 ionic conductance with 5-hydroxymethyl-2furfural, 5-nitro-2-furoic acid, and 5-acetoxymethyl-2-furaldehyde but not with vehicle (DMSO) or methyl 5-nitro-2-furoate. Boxes contain $50 \%$ of the data points; bars show the full range of data values; horizontal bars show the median value. $n$ values are above the $x$-axis. Statistical comparisons used two-tailed paired $t$ tests within treatment groups. (B) Structures of the compounds tested. Statistical comparisons are indicated as $P<0.0001$ $(* * *) ; P<0.001(* *)$; or N.S. $(P \geq 0.05)$; see Methods for details.

approximately $40 \%$ confluence under normal culture conditions and transferred into reduced serum (2\% FBS) DMEM medium for 32-34 hours before seeding. Corning Transwell polycarbonate membrane cell culture inserts $(8-\mu \mathrm{m}$ pore size; product \#3422; Sigma-Aldrich) were prepared by coating the upper surface of the filter with $40 \mu \mathrm{l}$ of extracellular matrix-like gel from EngelbrethHolm-Swarm murine sarcoma (diluted to $25 \mu \mathrm{g} / \mathrm{ml}$ in sterile water; Sigma-Aldrich), allowed to dry overnight in a sterile hood, and then rehydrated with $50 \mu \mathrm{l}$ of serum-free DMEM 2 hours before cell seeding. In the lower chamber, $600 \mu \mathrm{l}$ of DMEM with $10 \%$ serum (chemoattractant) was added with or without the vehicle or furan agents. Cells were seeded into the upper chamber at $2.5 \times 10^{5}$ cells per well for HT29, $1.5 \times 10^{5}$ cells per well for SW480, and $1 \times 10^{5}$ cells per well for MDA in serum-free DMEM, with DMSO or furan agents matching in the lower chamber. Durations of incubations for Transwell assays were optimized empirically in previous work (Nourmohammadi et al., 2019); durations used were 6 hours for MDA and 24 hours for HT29 and SW480, at $37^{\circ} \mathrm{C}$ in $5 \% \mathrm{CO}_{2}$. For quantitation of invasion, nonmigrated cells were wiped from the upper surface of the membrane with a cotton swab; migrated cells on the trans (lower) surface were counted after staining with crystal violet (Sigma-Aldrich). Numbers of migrated cells were determined for three fields per replicate, with two replicates per 

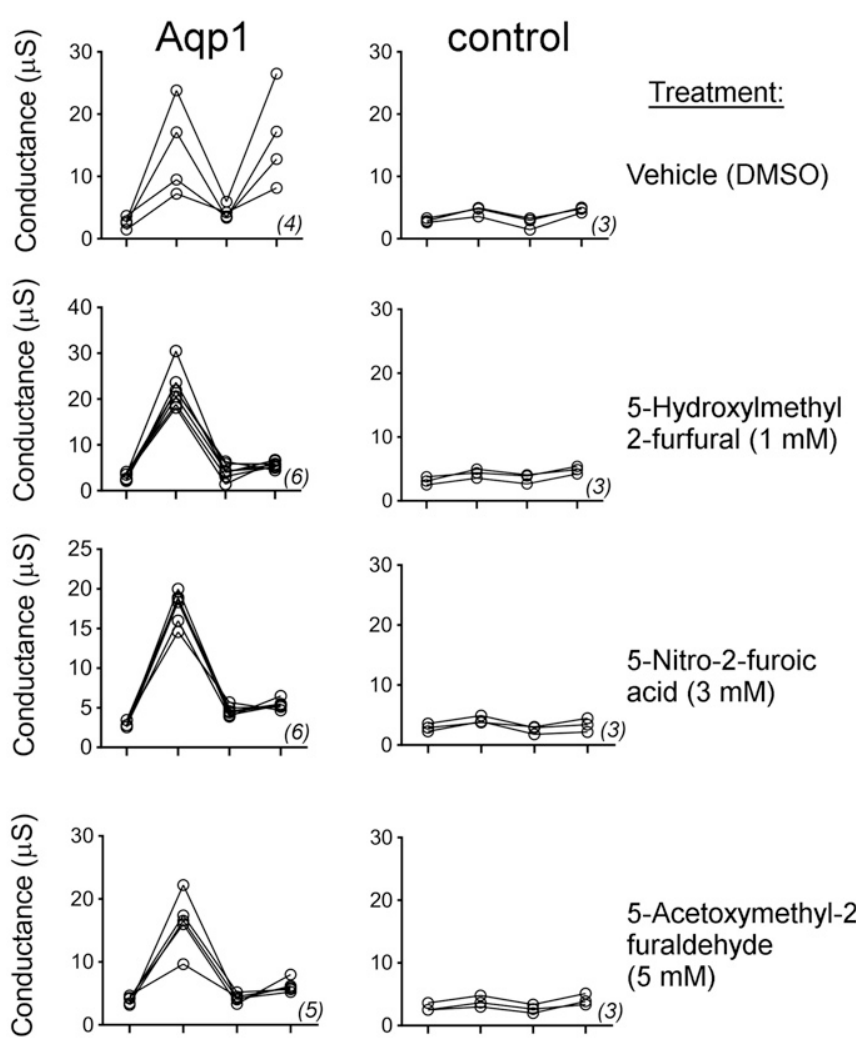

5-Acetoxymethyl-2furaldehyde (5 mM)
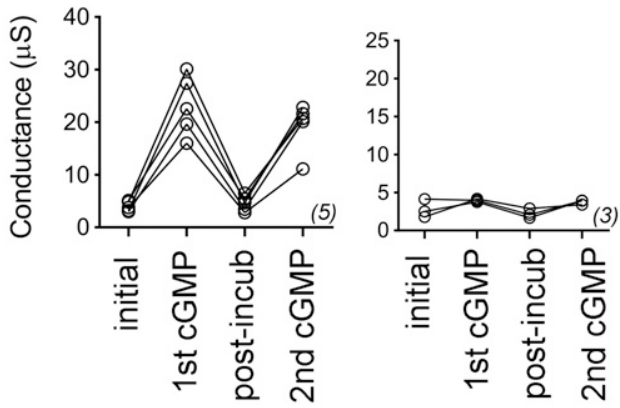

Fig. 3. Trend plots showing the effects of $5 \mathrm{HMF}$ and related compounds on ion conductances. Conductance values were measured for AQP1expressing (left) and non-AQP-expressing (right) oocytes. Lines link the values for single oocytes recorded before 8CPT-cGMP (initial), 30 minutes after 8CPT-cGMP ("1st cGMP"), after 2-hour incubation in saline with vehicle or furan compounds without cGMP ("post-incub"), and after reapplication of 8CPT-cGMP ("2nd cGMP"). Treatments (listed right) were applied during the 2-hour recovery interlude between "1st cGMP" and "post-incub" steps. $n$ values are shown in italics above the $x$-axis.

experiment, and normalized to the mean number of migrated cells in the vehicle control treatment of the same cell line.

Cell Viability Assay. HT29, MDA, and SW480 cell viabilities were assessed using the alamarBlue assay (Molecular Probes, Eugene, OR). Cells were plated at $10^{4}$ cells per well in 96 -well plates, and fluorescence signals were measured with a FLUOstar Optima microplate reader (BMG Labtech, Ortenberg, Germany) after 24 hours of incubation with vehicle, $5 \mathrm{HMF}$, or related furan compounds.

Actin Staining. HT29, SW480, and MDA cells were cultured in $\mu$-plate eight-well dishes (Ibidi, Munich, Germany) in 2\% FBS with 5fluoro-2'-deoxyuridine $(400 \mathrm{nM})$ and incubated at $37^{\circ} \mathrm{C}$ in $5 \% \mathrm{CO} 2$. After 12-18 hours of incubation, cells were treated with DMSO (vehicle) or furan derivatives and incubated for another 24 hours. Cells were then washed with PBS and fixed with $4 \%$ paraformaldehyde at room temperature for 10-30 minutes. Fixed cells were rinsed two to three times with PBS and permeabilized with $200 \mu \mathrm{l}$ of
$0.1 \%$ Triton X-100 in PBS for 3-5 minutes at room temperature. Phalloidin-iFluor 488 Reagent CytoPainter (ab176753; Abcam, MA) at 1:1000 dilution was used to stain F-actin cytoskeleton at room temperature in the dark for 1-2 hours. Hoechst stain (diluted 1: 1000; catalog \# 861405; Sigma-Aldrich) was used to label cell nuclei. Cells were visualized using an SP5 laser scanning confocal microscope (Leica, Germany) at Adelaide Microscopy core facilities.

Quantitative Polymerase Chain Reaction Analysis of AQP1 Expression. HT29, SW480, and MDA cells were seeded in triplicate at $4 \times 10^{5}$ cells per well in six well plates and incubated at $37^{\circ} \mathrm{C}$ in humidified $5 \% \mathrm{CO}_{2}$ environment overnight. The PureLink RNA Mini Kit (Invitrogen, Carlsbad, CA) was used for total RNA extraction for all cancer cell lines. cDNA was synthesized from $1 \mu \mathrm{g}$ of extracted RNA using QuantiTect Reverse Transcription Kit (Qiagen, Hilden, Germany). Synthesized cDNA was quantified using a NanoDrop (Life Technologies, Carlsbad, CA). A final concentration of $50 \mathrm{ng}$ cDNA was used to perform real-time quantitative Reverse Transcription-PCR analyses using SYBR Green PCR Master Mix (Applied Biosystems,
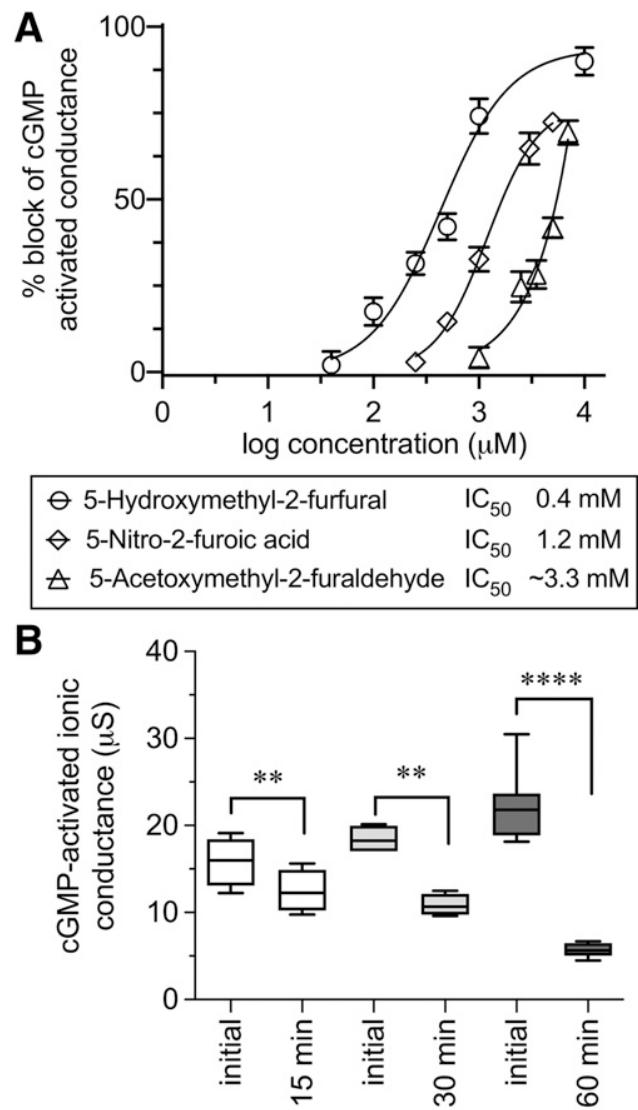

duration of $5 \mathrm{HMF}$ treatment $(1 \mathrm{mM})$

Fig. 4. Dose dependence and rate of onset of block of the cGMP-activated AQP1 ionic conductance. (A) Dose-response curves showing mean percent block ( \pm S.E.M.) as a function of concentration of the furan compounds. Estimated $\mathrm{IC}_{50}$ values are listed in the legend. $n$ values were three per dose for 5-hydroxymethyl-2-furfural (except $1 \mathrm{mM}$ which was $n=7$ ), three per dose for 5-nitro-2-furoic acid, and three per dose for 5-acetoxymethyl-2furaldehyde (except $5 \mathrm{mM}$, which was $n=4$ ). $n$ values indicate individual oocytes; data were combined from four batches of oocytes. (B) Time of onset of block of AQP1 ionic conductance during incubation in $1 \mathrm{mM} 5 \mathrm{HMF}$. The mean level of inhibition of the AQP1 ionic conductance ( \pm S.D.) was $21 \% \pm$ $3 \%$ at 15 minutes $(n=4), 41 \% \pm 6 \%$ at 30 minutes $(n=4)$, and $75 \% \pm 5 \%$ at 60 minutes $(n=8)$ of incubation time. $n$ values indicate individual oocytes; data were combined from two batches of oocytes. Statistical analyses used two-tailed paired $t$ tests to compare initial and second timepoints for the same oocytes. Statistical comparisons are indicated as $P<0.00001$ (****);

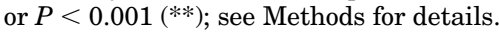




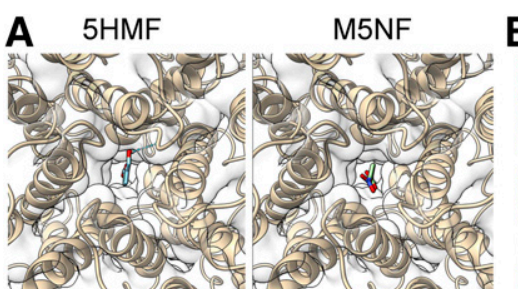

$5 \mathrm{AMF}$ 5NFA
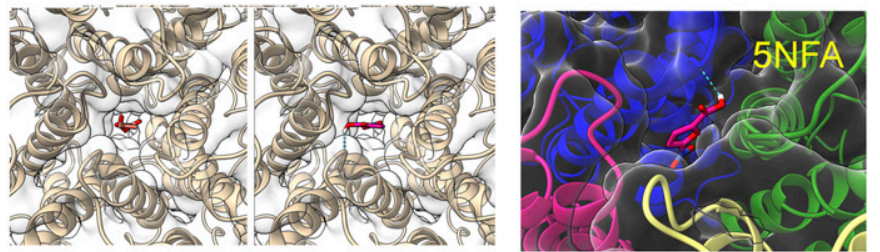

Fig. 5. In silico modeling of predicted binding sites for $5 \mathrm{HMF}$ and related compounds. (A) Docking modeling results suggested the most favorable energy of interaction for the ligands was in the loop $\mathrm{D}$ domains, which surround the tetrameric central pore. Glycine 165 in human AQP1 is predicted to interact by hydrogen bonding (blue dotted line) with polar aldehyde or acid moieties of $5 \mathrm{HMF}$ and $5 \mathrm{NFA}$, respectively. 5AMF and M5NF appeared to fit into the central pore domain, but specific amino acid interactions were not identified by the model. (B) Magnified views of hydrogen bonding interactions for 5HMF and 5NFA with Gly165 as predicted by in silico modeling.

Foster City, CA). StepOne Plus real-time PCR software was used for data analysis. The primer sequences used for AQP1 were forward 5' CGCAGAGTGTGGGCCACATCA- $3^{\prime}$ and reverse $5^{\prime}$-CCCGAGTTC ACACCATCAGCC - 3', amplifying a product of $217 \mathrm{bp}$. Ribosomal protein S13 (RPS13) was used as a standard, and target mRNA levels relative to RPS13 were calculated from the differences in cycle thresholds quantified using the individual-efficiencycorrected method.

Data Analysis and Statistics. Results compiled from replicate experiments are presented as box plots to show the full range of data points. Boxes represent $50 \%$ of the data, the error bars indicate the full range, and the horizontal bar is the median value. Statistical differences were evaluated using one-way ANOVA, paired or unpaired Student's $t$ tests, or Dunnett's Multiple Comparisons as indicated.

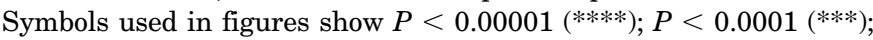

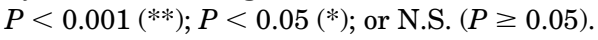

\section{Results}

Effects of Furan Compounds on the AQP1 Ion Channel Conductance. Effects of 5HMF and three structurally related compounds (5NFA, 5AMF, and M5NF) were assessed using two-electrode voltage clamp to record ion conductance amplitudes in AQP1-expressing oocytes (Fig. 1). Currents were measured before ("initial") and 30 minutes after activation by 8CPT-cGMP ("cGMP first"). Oocytes were then incubated 2 hours in isotonic saline with vehicle or the indicated agents. During the incubation period (without 8CPT-cGMP present), the ionic conductance recovered to initial levels as described previously (Kourghi et al., 2016). Incubation with the vehicle (DMSO) did not impair the second conductance response to 8CPT-cGMP ("cGMP second"). Responses were inhibited after incubation in 5HMF or 5NFA at $1 \mathrm{mM}$, and partially in 5AMF at $3 \mathrm{mM}$. No appreciable block was observed after incubation with M5NF (5 mM).

Compiled data for conductance responses (Fig. 2) show amplitudes of cGMP-activated conductances in AQP1-expressing oocytes, with each oocyte measured before and after incubation with vehicle or a furan derivative, as indicated. Paired $t$ tests were used for statistical comparisons with treatment groups. Conductance responses to cGMP were reduced after treatment with $5 \mathrm{HMF}, 5 \mathrm{NFA}$, or $5 \mathrm{AMF}$ as compared with the initial cGMP-activated responses in the same oocytes (Fig. 2A). M5NF was not effective. Structures of the furan derivatives are illustrated in Fig. 2B. The active agents have a carboxylic acid (5NFA) or aldehyde (5HMF, 5AMF) group on the furan ring; methylation of the carboxylic acid group in M5NF correlated with absence of any apparent inhibition of AQP1 ion channels.

Trend plots (Fig. 3) summarize conductance responses measured by two-electrode voltage clamp for AQP1-expressing and non-AQP-expressing (control) oocytes. Initial conductances in AQP1-expressing and control oocytes were similarly low before addition of 8CPT-cGMP. After application of the agonist
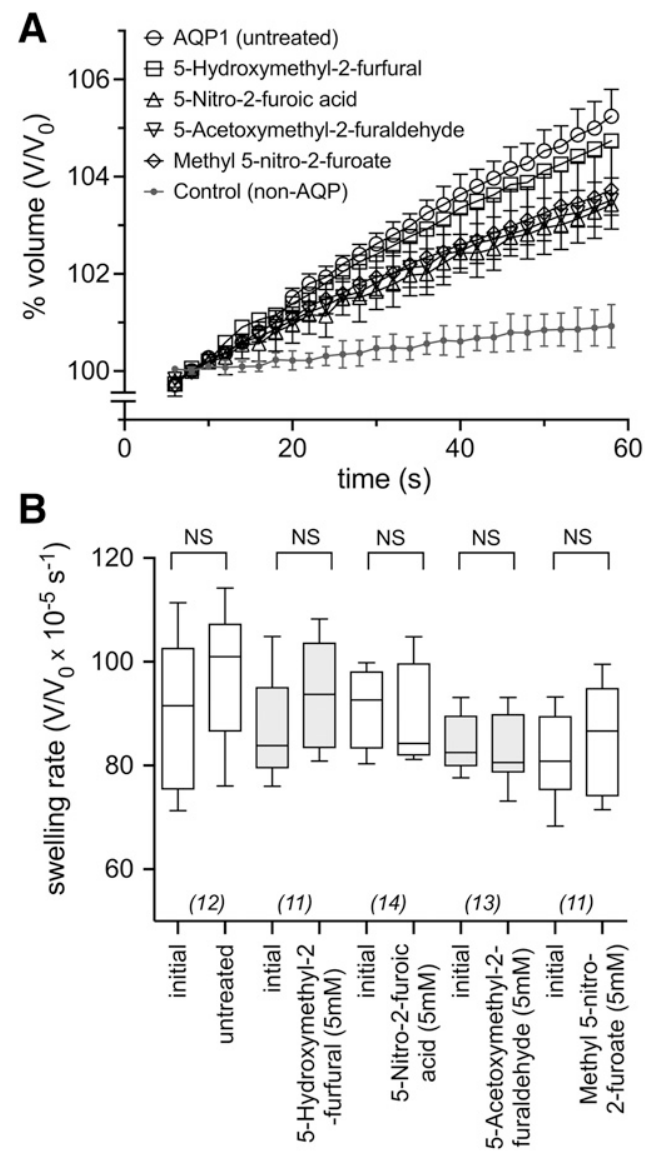

Fig. 6. Osmotic water permeability of AQP1-expressing oocytes is not altered by treatment with $5 \mathrm{HMF}$ or related compounds. (A) Osmotic swelling was monitored as the increase in oocyte volume, standardized to initial volume, as a function of time after introduction of each oocyte into $50 \%$ hypotonic saline at time zero. Data are means \pm S.E.M. The control $n$ value was 10; other $n$ values were as shown in B. (B) Linear regression fits of responses (illustrated in A) were used to calculate slope values indicating swelling rates, which were compiled into a box plot. Swelling rates of AQP1-expressing oocytes were measured before (initial) and after 2 hours of incubation in saline with vehicle or $5 \mathrm{mM}$ furan compounds as indicated. Boxes show $50 \%$ of the data; whiskers show the full range; horizontal bars are median values; $n$ values are in italics above the $x$-axis. None of the treatment groups showed responses that were different from untreated, based on ANOVA $P=0.1799$ and two-tailed paired $t$ tests within treatment groups. Statistical comparisons indicating no significant difference are shown as NS $(P \geq 0.05)$; see Methods for details. 
A
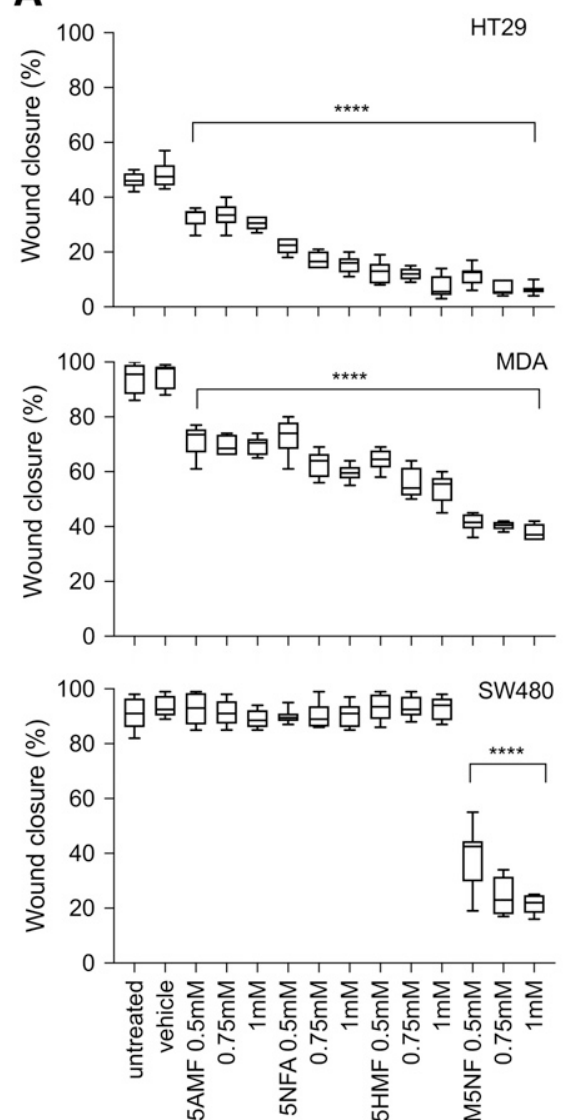

B
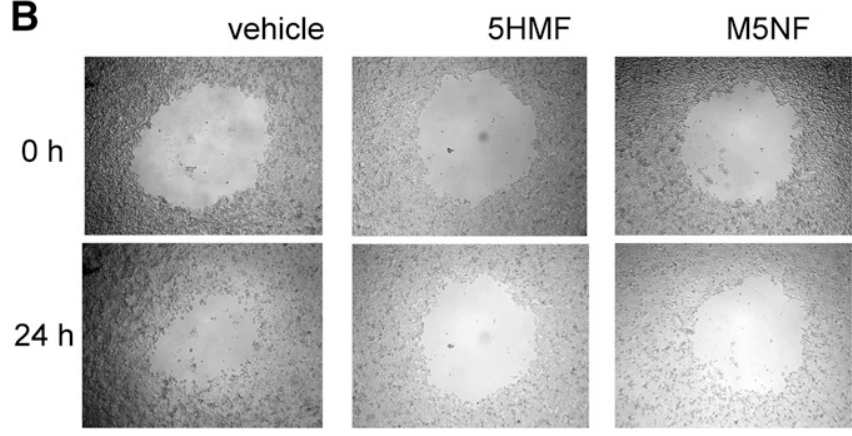

C

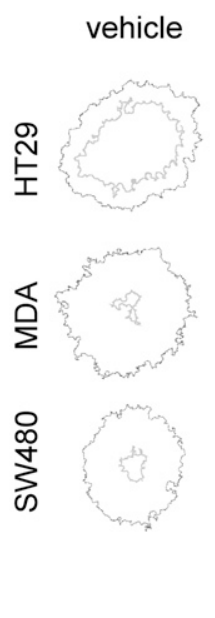

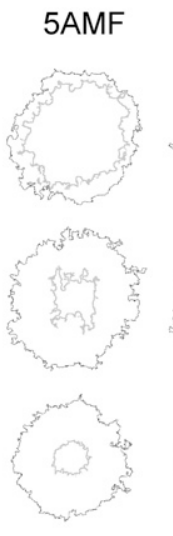
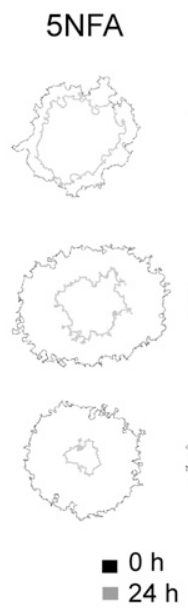
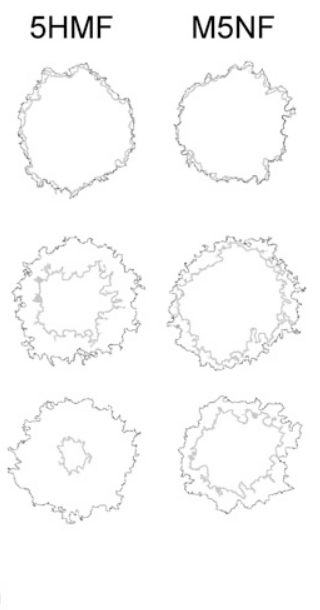

Fig. 7. Circular wound closure in HT29, MDA, and SW480 cells is differentially impaired by $5 \mathrm{HMF}$ and related compounds. (A) Box plots depicting results for percent wound closure of HT29, MDA, and SW480 cells after treatment with or without vehicle or furan derivatives. HT29 and MDA showed block by all compounds; SW480 was sensitive only to M5NF. $n=8$ for all groups except HT29 5NFA (0.75 mM) and HT29 M5NF (0.75 mM), which were $n=7$ each. Statistical analyses were done with one-way ANOVA and Dunnett's Multiple Comparisons tests for each column as compared with vehicle control. (B) Representative images showing circular wounds at 0 (upper row) and 24 hours (bottom row) in cultured HT29 cells treated with vehicle, $5 \mathrm{HMF}$, or M5NF. (C) Superimposed outlines of circular wound perimeters at 0 (black) and 24 (gray) hours for representative examples from each treatment group were generated by ImageJ software. Statistical comparisons are indicated as $P<0.00001$ (****); see Methods for details.

("first cGMP"), currents in AQP1-expressing oocytes increased to a maximum amplitude by approximately 30 minutes, whereas control oocytes showed no substantial effect of cGMP in the same timeframe. Oocytes were then transferred into incubation salines containing vehicle or the indicated furan derivatives for 2 hours. Initial ionic conductances recorded after the incubation period ("post-incub") were comparable to those in the starting initial condition, confirming that ion channel activation was reversible. Second applications of $8 \mathrm{CPT}$-cGMP in normal saline were used to assess levels of inhibition established during the incubation period. The AQP1 conductance was fully reactivated by 8CPT-cGMP ("second cGMP") after incubation in saline with vehicle, showing that repeated recordings were well tolerated. The impairment of $\mathrm{AQP} 1$ reactivation by cGMP after incubation in $1 \mathrm{mM} 5 \mathrm{HMF}, 3 \mathrm{mM} 5 \mathrm{NFA}$, or $5 \mathrm{mM} 5 \mathrm{AMF}$ indicated inhibition of the ionic conductance. M5NF showed no appreciable blocking effect. Non-AQP1-expressing control oocytes showed little or no effects of cGMP, vehicle, or furan derivatives.

The effects of the active furan derivatives on the AQP1 ionic conductance were dose-dependent and required time to establish (Fig. 4). Dose-response relationships (Fig. 4A) for percent block (mean \pm S.E.M.) provided estimated $\mathrm{IC}_{50}$ values for $5 \mathrm{HMF}(0.43 \mathrm{mM}), 5 \mathrm{NFA}(1.2 \mathrm{mM})$, and $5 \mathrm{AMF}(3 \mathrm{mM}$ or higher). The onset of block of the AQP1 conductance by $5 \mathrm{HMF}$ was not immediate, requiring time for establishment (Fig. 4B). 8CPT-cGMP-activated ion conductance responses were measured for the same AQP1-expressing oocytes at time zero and at a second time point thereafter. During the interlude, oocytes were incubated in $1 \mathrm{mM} 5 \mathrm{HMF}$ for 15,30 , or 60 minutes before being rinsed in standard saline and tested for reactivation with the second application of 8CPT-cGMP. Statistical comparisons were done with paired $t$ tests. The magnitude of block increased with longer times of incubation in $1 \mathrm{mM} 5 \mathrm{HMF}$, reaching near maximal block after 1 hour of incubation (Fig. 4B). The time needed to establish block was consistent with a predicted intracellular site of action of $5 \mathrm{HMF}$ at the AQP1 channel. Similar latencies for onset of block (1 to 2 hours) have been described for agents such as AqB013, AqB011, and bacopasides that act at the intracellular side of the AQP1 channel (Migliati et al., 2009; Kourghi et al., 2016; Pei et al., 2016b) and require time to cross the plasma membrane.

In silico docking analyses were used to investigate candidate sites for interaction of the ligand 5HMF with the human AQP1 channel (Fig. 5). Views from the intracellular side of the channel show the site that emerged as having the most favorable energy of interaction was in the loop D regions, which surround the intracellular face of the central pore 

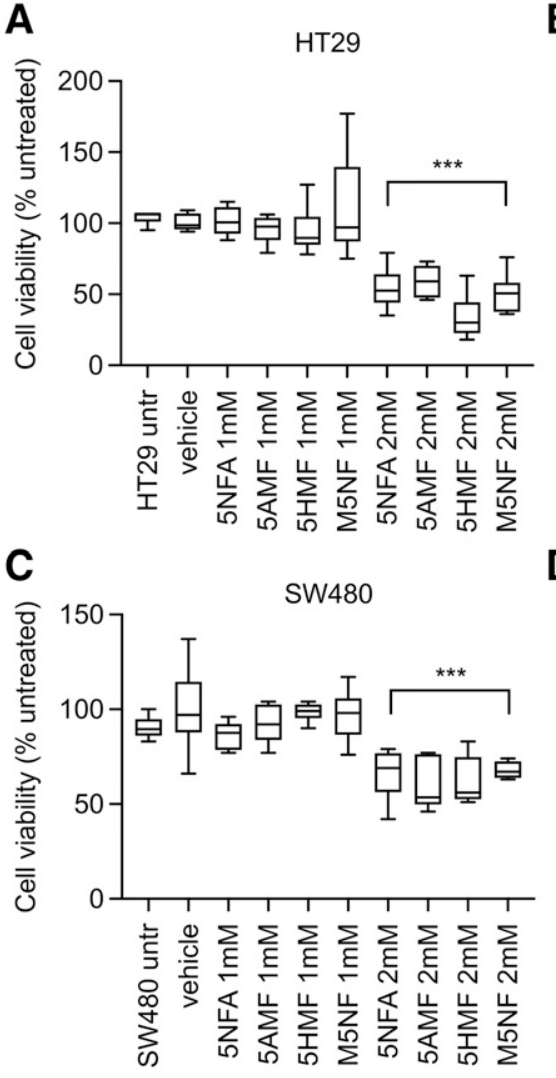

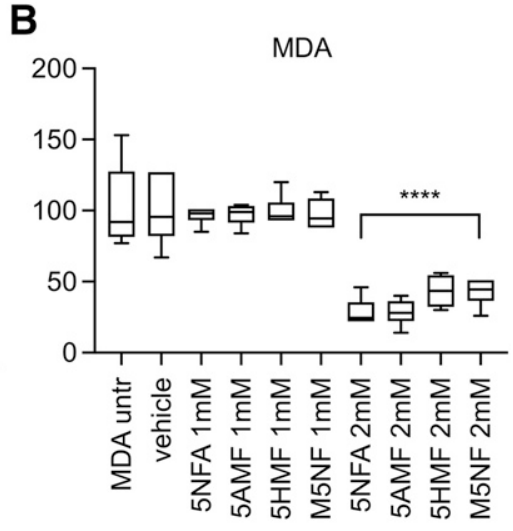

D

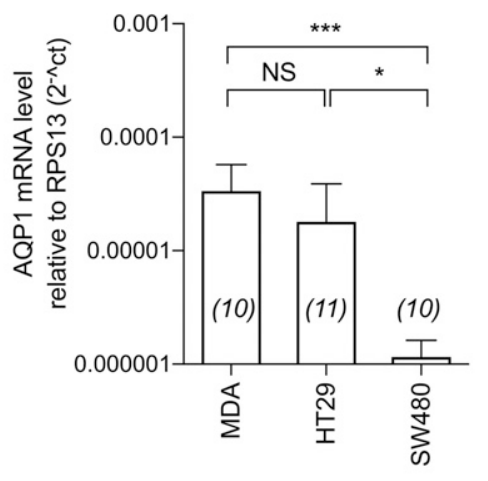

Fig. 8. Analysis of dose-dependent cytotoxic effects of treatments and confirmation of AQP1 mRNA expression levels in the cancer cell lines. Cell viability shown in box plot summaries was measured by alamarBlue assay for (A) HT29, (B) MDA, and (C) SW480 cells. Data were standardized to results for untreated cells. Statistical analyses were done with one-way ANOVA and Dunnett's Multiple Comparisons tests for each column as compared with vehicle control. $n=6$ in all treament groups. (D) AQP1 transcript levels, standardized to transcript levels of RPS13, were higher in HT29 and MDA than in SW480, as determined by quantitative reverse-transcription PCR. Histogram bars show means \pm S.D.; $n$ values are indicated in italics. Statistical comparisons are indicated as $P<0.00001$ (****); $P<0.0001$ (***); $P<0.05$ (*); or N.S. $(P \geq 0.05)$; see Methods for details.
(Fig. 5A). These cytoplasmic loops, connecting the fourth and fifth transmembrane domains of each subunit, modulate AQP channel gating (Yu et al., 2006; Nyblom et al., 2009; Kourghi et al., 2018). In silico models of predicted binding sites for $5 \mathrm{HMF}$ and 5NFA suggest formation of hydrogen bond interactions between the ligand and glycine 165 (Fig. 5B), a residue conserved in AQP1 amino acid loop D sequences across species (Kourghi et al., 2018). Predicted energies of interaction ( $\mathrm{kcal} / \mathrm{mol}$ ) estimated from the in silico docking model were 5HMF $(-4.9)$, 5NFA, (-4.3), 5AMF (-4.0), and M5NF (-3.9).

Effects of Furan Compounds on AQP1 Osmotic Water Fluxes. The furan derivatives did not inhibit AQP1 osmotic water permeability (Fig. 6). Oocytes expressing AQP1 and non-AQP1 control oocytes were assessed for osmotic water permeability as quantified by swelling rates in $50 \%$ hypotonic saline (Fig. 6A) as per published methods (Migliati et al., 2009). Swelling rates were measured for the same oocytes before and after treatment with furan compounds (Fig. 6B). $\mathrm{AQP} 1$-expressing and non-AQP control oocytes were tested in initial swelling assays and then transferred into isotonic saline with DMSO vehicle ("untreated") or with furan derivatives ( $5 \mathrm{mM}$ ) for 1 hour. After incubation, oocytes were rinsed briefly in saline and tested again for swelling in hypotonic saline. Based on paired $t$ test evaluations within treatment groups, there were no differences between the first and second swelling rates (Fig. 6B), indicating that none of the furan compounds appreciably affected AQP1 water permeability.

Effects of Furan Derivatives on Cancer Cell Migration Rates. Effects of the furan derivatives on the migration of breast and colon cancer cell lines were tested using a circular wound closure assay. Results in Fig. 7 show that HT29 cell migration was reduced by furan derivatives as compared with vehicle control. Cell migration was reduced $85 \%$ by $5 \mathrm{HMF}$ $(P<0.0001), 68 \%$ by $5 \mathrm{NFA}(P<0.0001)$, and $37 \%$ by $5 \mathrm{AMF}$ $(P<0.0001)$ (each at $1 \mathrm{mM})$, indicating that the agents that were found to block the AQP1 ion conductance were also effective in reducing motility. A similar pattern was observed for MDA cell migration, which was reduced $43 \%$ by $5 \mathrm{HMF}(P<$ $0.0001), 37 \%$ by $5 \mathrm{NFA}(P<0.0001)$, and $27 \%$ by $5 \mathrm{AMF}(P<$ $0.0001)$. In contrast, SW480 cells showed no sensitivity to 5HMF $(P=0.9997)$, 5NFA $(P=0.929)$, or 5AMF $(P=0.4849)$, with migration rates comparable to that of vehicle control and consistent with the low level of membrane AQP1 protein in the SW480 cell line. However, M5NF (which did not affect AQP1 water or ion channel activities), unexpectedly inhibited migration in all three cell lines, reducing HT29 cell migration by $87 \%(P<0.0001)$, SW480 by $77 \%(P<0.0001)$, and MDA by $60 \%(P<0.0001)$. These results suggest that M5NF targets a widespread process that is required for cell motility but is not mediated by AQP1.

Cell metabolic activity as an estimator of viability was measured with the alamarBlue assay, with results normalized to metabolic activity levels of vehicle-treated groups in the same cell lines (Fig. 8). Metabolic activity was not impaired by $5 \mathrm{HMF}$ or related compounds at $1 \mathrm{mM}$ in any of the cell lines (Fig. 8, A-C), suggesting the reduced cancer cell motility seen at this concentration could not be attributed primarily to reduced cell viability. Furan derivatives did impair metabolic activity at higher concentration $(2 \mathrm{mM})$ in all cell lines, suggesting an upper limit for a potential therapeutic window, depending on cell type. Oocytes showed no evidence of toxicity from any of the agents at any of the doses tested (up to $5 \mathrm{mM}$ ), 
A
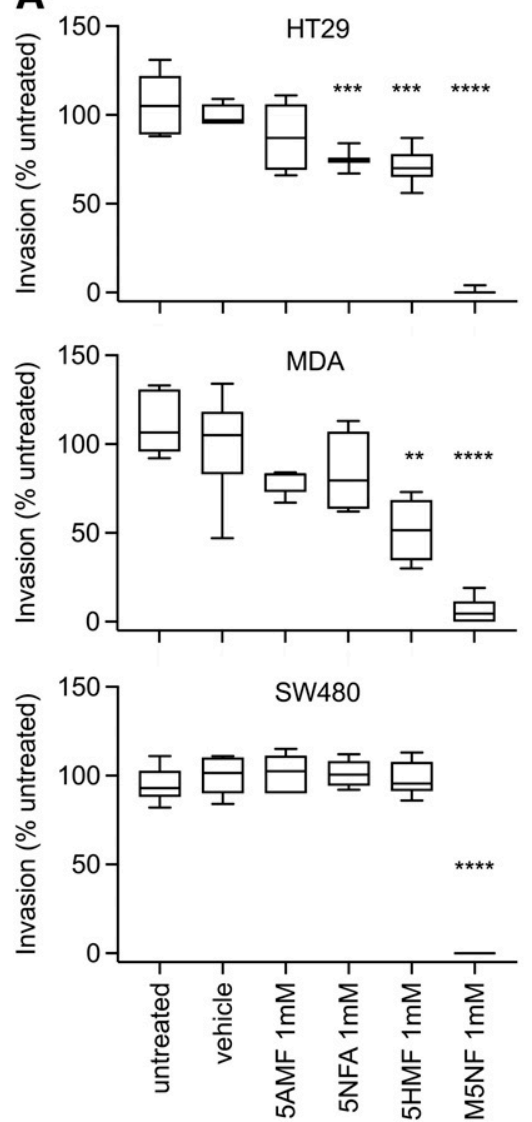

B

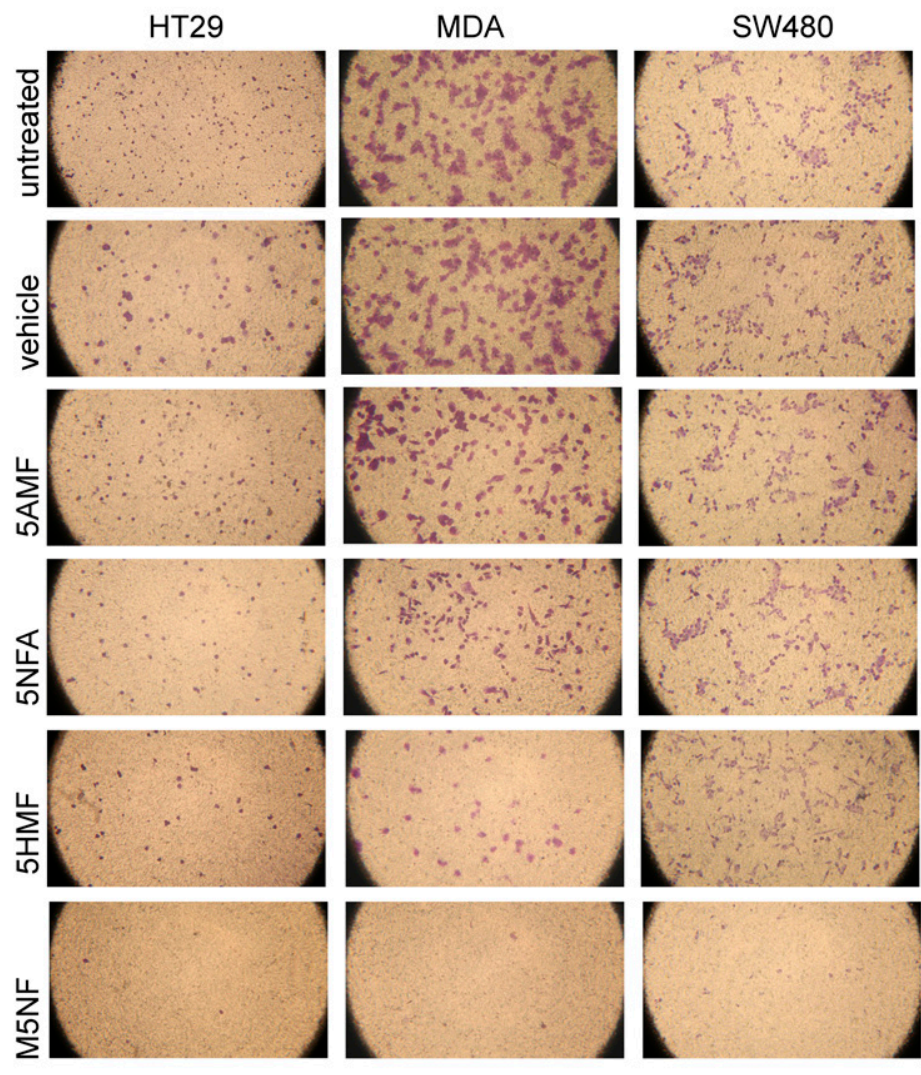

Fig. 9. Effects of 5HMF and related compounds on Transwell cell invasiveness of HT29, MDA, and SW480 cells. (A) Box plots depicting HT29, MDA, and SW480 cell migration across Transwell filters with extracellular matrix with or without treatment with vehicle or furan derivatives at $1 \mathrm{mM}$ as indicated. Statistical comparisons were done with ANOVA and unpaired $t$ tests compared with vehicle controls. $n$ values are seven each per treatment group for HT29 and six each per treatment group for SW480 and MDA. (B) Images illustrating differences in the abundance of successfully migrated cells (stained purple) on the trans sides of filters for the three cell lines untreated and in the different treatment conditions (at $1 \mathrm{mM}$, or equivalent DMSO for vehicle).

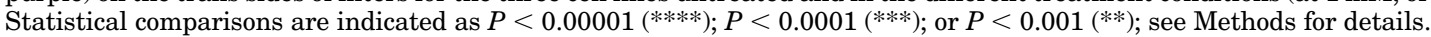

based on the observed maintenance of normal low ionic conductances in non-AQP1 control oocytes throughout the treatment protocols (Fig. 3), normal appearance, and typical resting membrane potentials (data not shown).

Levels of AQP1 transcript measured using quantitative PCR were confirmed to be high in MDA and HT29 cell lines and low in SW480 cells (Fig. 8D), consistent with results reported previously (Pei et al., 2016b, 2019; Nakhjavani et al., 2019). The low level of AQP1 protein that is expressed in SW480 cells has been shown to be mainly intracellular, consistent with the insensitivity of these cells to effects of AQP1 channel blockers (De Ieso et al., 2019).

Effects of Furan Derivatives on Cancer Cell Invasiveness. The effect of furan derivatives on cancer cell invasiveness was tested using a Transwell invasion assay, in which cells migrated through an extracellular matrix-like material layered on a semipermeable membrane toward a chemoattractant (FBS) and then were stained with crystal violet and counted on the trans-side of the filter (Fig. 9). HT29 cell invasiveness was impaired $30 \%$ by $5 \mathrm{HMF}(P<0.001)$ and $25 \%$ by $5 \mathrm{NFA}(P<0.001)$, as compared with vehicle control; 5AMF $(P=0.1175)$ was not effective. In MDA cells, invasion was blocked $49 \%$ by $5 \mathrm{HMF}(P<0.001)$; NFA $(P=0.6415)$ and 5AMF ( $P=0.9858)$ were not effective. SW480 cells showed no block of invasion by 5HMF ( $P=0.9958), 5 \mathrm{NFA}(P=0.9996)$, or
5AMF $(P=0.9971)$. However, M5NF intriguingly caused almost complete block of invasion in all three cell lines, suggesting effects on a ubiquitous motility mechanism.

Effect of Furan Derivatives on Actin Polymerization. Pathways involved in cancer cell motility and metastasis are frequently found to include kinase and GTPase signaling cascades that converge on the regulation of actin cytoskeletal organization (Foxall et al., 2016). To examine the effects of M5NF on F-actin polymerization as an endpoint (Hinz and Jucker, 2019), HT29, MDA, and SW480 cells were treated with furan derivatives and then labeled with fluorescent phalloidin, which binds F-actin polymers with high affinity and reveals actin parallel fiber and network structures (Wulf et al., 1979).

Confocal imaging showed that fluorescence signal intensities were reduced in all three cell lines after treatment with M5NF, which disrupted the transverse parallel fiber tracts of actin, leaving trace residual staining against cell boundaries (Fig. 10). In contrast, treatments of HT29, MDA, and SW480 cells with the other furan derivatives had no discernable effects on actin signal intensity or structural organization as compared with vehicle control or untreated. M5NF effects on cell motility were distinct from those of the other furan derivatives and appeared to involve pathways controlling actin organization or assembly. 


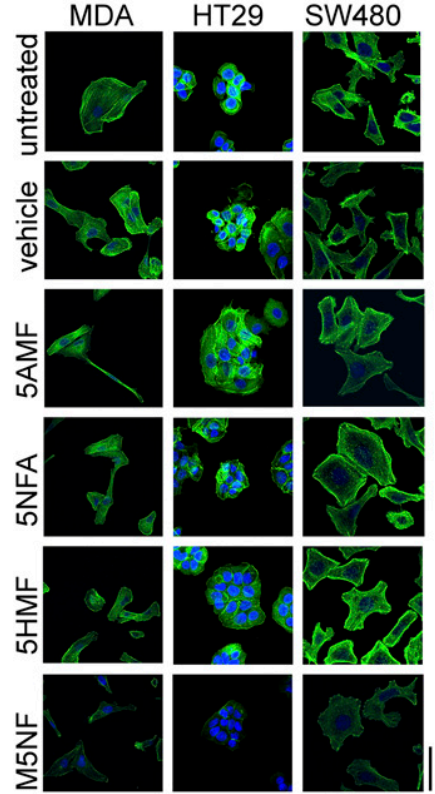

Fig. 10. Abundance and patterns of distribution of polymerized F-actin seen in MDA, HT29, and SW480 cells after treatment with or without vehicle or furan derivatives. F-actin was labeled with fluorescently tagged phalloidin (green). Nuclei were visualized by Hoechst stain (blue). Fluorescence signal intensities and the apparent organization of filaments into parallel strands were visibly reduced in cells treated with M5NF but not those treated with other furan compounds or vehicle. Scale bar, $25 \mu \mathrm{m}$ (lower right).

\section{Discussion}

AQP1 is upregulated in classes of breast, glioblastoma, colorectal, and other cancers and has been suggested to correlate with poor prognoses (El Hindy et al., 2013; Yoshida et al., 2013; Wang et al., 2017; Luo et al., 2018; Shimasaki et al., 2018). The dual water and ion channel function of AQP1 facilitates cancer cell migration and invasiveness in vitro (Kourghi et al., 2016; Pei et al., 2016b; De Ieso et al., 2019; Tomita et al., 2019), suggesting this channel might be of interest when considering new approaches to control cell motility (De Ieso and Yool, 2018). Fifteen classes of AQP (AQP0-14) have been identified to date in mammals (Denker et al., 1988; Preston and Agre, 1991; Ishibashi et al., 2009; Finn et al., 2014). Furans remain to be tested on other classes of AQPs. AQP1 expression has been linked to migration in certain aggressive cancer subtypes and has been proposed as a potential target for treatments to restrain cancer metastasis (Hu and Verkman, 2006; McCoy and Sontheimer, 2007; Jiang et al., 2009; Dorward et al., 2016; Pei et al., 2016a; De Ieso and Yool, 2018). In these cancer subtypes, AQP1 is localized at the leading edges of the migrating cells (McCoy and Sontheimer, 2007; Pei et al., 2019), where it is thought to facilitate rapid volume changes during process extension and retraction (Verkman et al., 2008; Yool and Campbell, 2012).

$5 \mathrm{HMF}$ is a naturally occurring compound in alternative medicinal treatments, with diverse reported effects, including benefits in some edema-associated conditions. This study tested the hypothesis that 5HMF might act as an inhibitor of AQP1 water or ion channel activities. Results showed that $5 \mathrm{HMF}$ blocked the cationic conductance of AQP1 with an $\mathrm{IC}_{50}$ value of approximately $400 \mu \mathrm{M}$, but it did not alter water channel activity. The AQP1 ion current was also inhibited by
5NFA and 5AMF; however, no AQP1 inhibition was observed with M5NF. Excluding M5NF, the AQP1-inhibitory efficacy appeared to be inversely related to the size of the moiety at position 5 on the furan ring; the most potent agent, $5 \mathrm{HMF}$, has the smallest group (hydroxy-methyl), and the least effective agent, 5AMF, has the largest group (acetoxy-methyl), although other differences could also be important. The methyl ester group on M5NF would be expected to increase relative hydrophobicity, and if anything, enhance membrane permeability and thus access to a proposed intracellular binding site; however, this feature did not rescue any AQP1 channel blocking effect. An amino acid predicted by in silico docking to be involved in ligand interaction is glycine 165, located in the loop $\mathrm{D}$ domain, a region which has been suggested to gate $\mathrm{AQP}$ channel activities (Tornroth-Horsefield et al., 2006; Yu et al., 2006; Kourghi et al., 2018). Predicted interactions of other ligands with loop D similarly have been correlated with inhibition of AQP1 ion channel activity (Kourghi et al., 2016; Pei et al., 2016b). Results here are consistent with the idea that furan ligands do not interact with intrasubunit pores to alter osmotic water fluxes but could alter loop D gating to inhibit ion conductance through the central pore.

Several lines of evidence support the conclusion that $5 \mathrm{HMF}$ and certain structural analogs pharmacologically target the AQP1 ion channel directly to slow migration and invasion in AQP1-expressing cancer cell lines. The highAQP1-expressing cell lines HT29 and MDA were sensitive to furan-based AQP1 ion channel blockers, whereas the lowAQP1-expressing cell line SW480 was not. The absence of effects of 5HMF, 5NFA, and 5AMF on SW480 cells showed that the agents did not impair motility indirectly via general cytotoxicity. Histologic analyses ruled out the idea that AQP1blocking furans impaired migration indirectly by disrupting cytoskeleton. Furan compounds at $5 \mathrm{mM}$ did not alter osmotic water fluxes in oocytes, confirming that the pharmacological treatments did not reduce $\mathrm{AQP} 1$ protein levels in oocyte plasma membranes, nor did they disrupt AQP1 tetrameric subunit organization which is a prerequisite for water channel activity (Jung et al., 1994). In contrast, M5FA impaired migration through a general mechanism that did appear to involve actin disorganization.

In summary, results here showed that $5 \mathrm{HMF}$ and related furan compounds 5NFA and 5AMF are AQP1 ion channel blockers. The level of pharmacological inhibition is dosedependent and differs between compounds, suggesting a chemical structure-activity relationship. Cancer wound closure and invasion are inhibited by AQP1-blocking furan derivatives in AQP1-enriched cancer cell lines. These outcomes add support for the proposal that the ion channel function of AQP1 is an important component of mechanisms of migration in some classes of cells. Development of furan agents using $5 \mathrm{HMF}$ as a lead compound might have promise for the development of new AQP1-based therapeutics for selected cancers and other disorders.

\section{Acknowledgments}

We thank the South Australian core facility Adelaide Microscopy for access to confocal microscopy facilities and Jane Sibbons for microscopy training and assistance.

\section{Authorship Contributions}

Participated in research design: Chow, Kourghi, Yool. 
Conducted experiments: Chow, Kourghi, Pei, Nourmohammadi. Performed data analysis: Chow, Kourghi, Pei, Nourmohammadi, Yool. Wrote or contributed to the writing of the manuscript: Chow, Kourghi, Yool.

Reviewed and approved the final manuscript: Chow, Kourghi, Pei, Nourmohammadi, Yool.

\section{References}

Abel SDA, Dadhwal S, Gamble AB, and Baird SK (2018) Honey reduces the metastatic characteristics of prostate cancer cell lines by promoting a loss of adhesion. PeerJ 6:e5115.

Afrin S, Giampieri F, Gasparrini M, Forbes-Hernández TY, Cianciosi D, ReboredoRodriguez P, Manna PP, Zhang J, Quiles JL, and Battino M (2018) The inhibitory effect of Manuka honey on human colon cancer HCT-116 and LoVo cell growth. Part 2: induction of oxidative stress, alteration of mitochondrial respiration and glycolysis, and suppression of metastatic ability. Food Funct 9:2158-2170.

Agre P, Preston GM, Smith BL, Jung JS, Raina S, Moon C, Guggino WB, and Nielsen S (1993) Aquaporin CHIP: the archetypal molecular water channel. Am J Physiol 265:F463-F476.

Ahmed S and Othman NH (2013) Review of the medicinal effects of tualang honey and a comparison with manuka honey. Malays J Med Sci 20:6-13.

Anthony TL, Brooks HL, Boassa D, Leonov S, Yanochko GM, Regan JW, and Yool AJ (2000) Cloned human aquaporin-1 is a cyclic GMP-gated ion channel. Mol Pharmacol 57:576-588.

Aryappalli P, Al-Qubaisi SS, Attoub S, George JA, Arafat K, Ramadi KB, Mohamed YA, Al-Dhaheri MM, Al-Sbiei A, Fernandez-Cabezudo MJ, et al. (2017) The IL-6/ STAT3 signaling pathway is an early target of manuka honey-induced suppression of human breast cancer cells. Front Oncol 7:167.

Attia WY, Gabry MS, El-Shaikh KA, and Othman GA (2008) The anti-tumor effect of bee honey in Ehrlich ascite tumor model of mice is coincided with stimulation of the immune cells. Egypt J Immunol 15:169-183.

Boassa D, Stamer WD, and Yool AJ (2006) Ion channel function of aquaporin-1 natively expressed in choroid plexus. J Neurosci 26:7811-7819.

Boassa D and Yool AJ (2003) Single amino acids in the carboxyl terminal domain of aquaporin-1 contribute to cGMP-dependent ion channel activation. BMC Physiol 3: 12 .

Byrt CS, Zhao M, Kourghi M, Bose J, Henderson SW, Qiu J, Gilliham M, Schultz C, Schwarz M, Ramesh SA, et al. (2017) Non-selective cation channel activity of aquaporin AtPIP2;1 regulated by $\mathrm{Ca}^{2+}$ and pH. Plant Cell Environ 40:802-815.

Campbell EM, Birdsell DN, and Yool AJ (2012) The activity of human aquaporin 1 as a cGMP-gated cation channel is regulated by tyrosine phosphorylation in the carboxyl-terminal domain. Mol Pharmacol 81:97-105.

De Ieso ML and Pei JV (2018) An accurate and cost-effective alternative method for measuring cell migration with the circular wound closure assay. Biosci Rep $\mathbf{3 8}$.

De Ieso ML, Pei JV, Nourmohammadi S, Smith E, Chow PH, Kourghi M, Hardingham JE, and Yool AJ (2019) Combined pharmacological administration of AQP1 ion channel blocker AqB011 and water channel blocker Bacopaside II amplifies inhibition of colon cancer cell migration. Sci Rep 9:12635.

De Ieso ML and Yool AJ (2018) Mechanisms of aquaporin-facilitated cancer invasion and metastasis. Front Chem 6:135.

Denker BM, Smith BL, Kuhajda FP, and Agre P (1988) Identification, purification, and partial characterization of a novel $\mathrm{Mr} 28,000$ integral membrane protein from erythrocytes and renal tubules. J Biol Chem 263:15634-15642.

Dorward HS, Du A, Bruhn MA, Wrin J, Pei JV, Evdokiou A, Price TJ, Yool AJ, and Hardingham JE (2016) Pharmacological blockade of aquaporin-1 water channel by AqB013 restricts migration and invasiveness of colon cancer cells and prevents endothelial tube formation in vitro. J Exp Clin Cancer Res 35:36.

El Hindy N, Rump K, Lambertz N, Zhu Y, Frey UH, Bankfalvi A, Siffert W, Sure U, Peters J, Adamzik M, et al. (2013) The functional Aquaporin 1 -783G/C-polymorphism is associated with survival in patients with glioblastoma multiforme. $J$ Surg Oncol 108:492-498.

Finn RN, Chauvigné F, Hlidberg JB, Cutler CP, and Cerdà J (2014) The lineagespecific evolution of aquaporin gene clusters facilitated tetrapod terrestrial adaptation. PLoS One 9:e113686.

Foxall E, Pipili A, Jones GE, and Wells CM (2016) Significance of kinase activity in the dynamic invadosome. Eur J Cell Biol 95:483-492.

Gasparrini M, Afrin S, Forbes-Hernández TY, Cianciosi D, Reboredo-Rodriguez P, Amici A, Battino M, and Giampieri F (2018) Protective effects of Manuka honey on LPS-treated RAW 264.7 macrophages. Part 2: control of oxidative stress induced damage, increase of antioxidant enzyme activities and attenuation of inflammation. Food Chem Toxicol 120:578-587.

Ghosh S and Playford RJ (2003) Bioactive natural compounds for the treatment of gastrointestinal disorders. Clin Sci (Lond) 104 (6):547-556.

Girma A, Seo W, and She RC (2019) Antibacterial activity of varying UMF-graded Manuka honeys. PLoS One 14:e0224495.

Gomes D, Agasse A, Thiébaud P, Delrot S, Gerós H, and Chaumont F (2009) Aquaporins are multifunctional water and solute transporters highly divergent in living organisms. Biochim Biophys Acta 1788:1213-1228.

Hazama A, Kozono D, Guggino WB, Agre P, and Yasui M (2002) Ion permeation of AQP6 water channel protein. Single channel recordings after $\mathrm{Hg}^{2+}$ activation. J Biol Chem 277:29224-29230.

He M, Grkovic T, Evans JR, Thornburg CC, Akee RK, Thompson JR, Whitt JA, Harris MJ, Loyal JA, Britt JR, et al. (2019) The NCI library of traditional Chinese medicinal plant extracts - preliminary assessment of the NCI-60 activity and chemical profiling of selected species. Fitoterapia 137:104285.

Hinz N and Jücker M (2019) Distinct functions of AKT isoforms in breast cancer: a comprehensive review. Cell Commun Signal 17:154
Hohmann I, Bill RM, Kayingo I, and Prior BA (2000) Microbial MIP channels. Trends Microbiol 8:33-38.

$\mathrm{Hu} \mathrm{J}$ and Verkman AS (2006) Increased migration and metastatic potential of tumor cells expressing aquaporin water channels. FASEB J 20:1892-1894.

Huber VJ, Tsujita M, and Nakada T (2012) Aquaporins in drug discovery and pharmacotherapy. Mol Aspects Med 33:691-703.

Ishibashi K, Hara S, and Kondo S (2009) Aquaporin water channels in mammals. Clin Exp Nephrol 13:107-117.

Jiang Q, Cao C, Lu S, Kivlin R, Wallin B, Chu W, Bi Z, Wang X, and Wan Y (2009) MEK/ERK pathway mediates UVB-induced AQP1 downregulation and water permeability impairment in human retinal pigment epithelial cells. Int $J \mathrm{Mol} \mathrm{Med}$ 23:771-777.

Jung JS, Preston GM, Smith BL, Guggino WB, and Agre P (1994) Molecular structure of the water channel through aquaporin CHIP. The hourglass model. J Biol Chem 269:14648-14654.

Khalil I, Moniruzzaman M, Boukraâ L, Benhanifia M, Islam A, Islam N, Sulaiman SA, and Gan SH (2012) Physicochemical and antioxidant properties of Algerian honey. Molecules 17:11199-11215.

Khan $\mathrm{H}$ (2014) Medicinal plants in light of history: recognized therapeutic modality. $J$ Evid Based Complementary Altern Med 19:216-219.

Kourghi M, De Ieso ML, Nourmohammadi S, Pei JV, and Yool AJ (2018) Identification of loop D domain amino acids in the human aquaporin-1 channel involved in activation of the ionic conductance and inhibition by AqB011. Front Chem 6:142.

Kourghi M, Pei JV, De Ieso ML, Flynn G, and Yool AJ (2016) Bumetanide derivatives AqB007 and AqB011 selectively block the aquaporin-1 ion channel conductance and slow cancer cell migration. Mol Pharmacol 89:133-140.

Kourghi M, Nourmohammadi S, Pei JV, Qiu J, McGaughey S, Tyerman SD, Byrt CS, and Yool AJ (2017) Divalent cations regulate the ion conductance properties of diverse classes of aquaporins. Int $J$ Mol Sci 18:11.

Lori G, Cecchi L, Mulinacci N, Melani F, Caselli A, Cirri P, Pazzagli L, Luti S, Mazzoli L, and Paoli P (2019) Honey extracts inhibit PTP1B, upregulate insulin receptor expression, and enhance glucose uptake in human HepG2 cells. Biomed Pharmacother 113:108752.

Luo L, Yang R, Zhao S, Chen Y, Hong S, Wang K, Wang T, Cheng J, Zhang T, and Chen D (2018) Decreased miR-320 expression is associated with breast cancer progression, cell migration, and invasiveness via targeting Aquaporin 1. Acta Biochim Biophys Sin (Shanghai) 50:473-480.

Martins AP, Ciancetta A, de Almeida A, Marrone A, Re N, Soveral G, and Casini A (2013) Aquaporin inhibition by gold(III) compounds: new insights. ChemMedChem 8:1086-1092.

McCoy E and Sontheimer H (2007) Expression and function of water channels (aquaporins) in migrating malignant astrocytes. Glia 55:1034-1043.

Migliati E, Meurice N, DuBois P, Fang JS, Somasekharan S, Beckett E, Flynn G, and Yool AJ (2009) Inhibition of aquaporin-1 and aquaporin-4 water permeability by a derivative of the loop diuretic bumetanide acting at an internal pore-occluding binding site. Mol Pharmacol 76:105-112.

Nakhjavani M, Palethorpe HM, Tomita Y, Smith E, Price TJ, Yool AJ, Pei JV, Townsend AR, and Hardingham JE (2019) Stereoselective anti-cancer activities of ginsenoside Rg3 on triple negative breast cancer cell models. Pharmaceuticals (Basel) 12

Nourmohammadi S, Aung TN, Cui J, Pei JV, De Ieso ML, Harata-Lee Y, Qu Z, Adelson DL, and Yool AJ (2019) Effect of compound kushen injection, a natura compound mixture, and its identified chemical components on migration and invasion of colon, brain, and breast cancer cell lines. Front Oncol 9:314.

Nyblom M, Frick A, Wang Y, Ekvall M, Hallgren K, Hedfalk K, Neutze R, Tajkhorshid E, and Törnroth-Horsefield S (2009) Structural and functional analysis of SoPIP2;1 mutants adds insight into plant aquaporin gating. $\mathrm{J} \mathrm{Mol} \mathrm{Biol} \mathrm{387}$ 653-668.

Pei JV, Burton JL, Kourghi M, De Ieso ML, and Yool AJ (2016a) Drug discovery and therapeutic targets for pharmacological modulators of aquaporin channels, in Aquaporins in Health and Disease: New Molecular Targets for Drug Discovery (Soveral G, Casinin A, and Nielsen S 275-297, CRC Press, Oxfordshire, UK.

Pei JV, Heng S, De Ieso ML, Sylvia G, Kourghi M, Nourmohammadi S, Abell AD, and Yool AJ (2019) Development of a photoswitchable lithium-sensitive probe to analyze nonselective cation channel activity in migrating cancer cells. Mol Phar macol 95:573-583.

Pei JV, Kourghi M, De Ieso ML, Campbell EM, Dorward HS, Hardingham JE, and Yool AJ (2016b) Differential inhibition of water and ion channel activities of mammalian aquaporin-1 by two structurally related bacopaside compounds derived from the medicinal plant Bacopa monnieri. Mol Pharmacol 90:496-507.

Preston GM and Agre P (1991) Isolation of the cDNA for erythrocyte integral membrane protein of 28 kilodaltons: member of an ancient channel family. Proc Natl Acad Sci USA 88:11110-11114.

Preston GM, Carroll TP, Guggino WB, and Agre P (1992) Appearance of water channels in Xenopus oocytes expressing red cell CHIP28 protein. Science 256: 385-387.

Reizer J, Reizer A, and Saier MH Jr. (1993) The MIP family of integral membrane channel proteins: sequence comparisons, evolutionary relationships, reconstructed pathway of evolution, and proposed functional differentiation of the two repeated halves of the proteins. Crit Rev Biochem Mol Biol 28:235-257.

Saparov SM, Kozono D, Rothe U, Agre P, and Pohl P (2001) Water and ion permeation of aquaporin-1 in planar lipid bilayers. Major differences in structural determinants and stoichiometry. J Biol Chem 276:31515-31520.

Seeliger D, Zapater C, Krenc D, Haddoub R, Flitsch S, Beitz E, Cerdà J, and de Groot BL (2013) Discovery of novel human aquaporin-1 blockers. ACS Chem Biol 8 $249-256$.

Shan Y (2019) Medicinal honey in clinical practice: viable alternative or useful adjunct in wound care management? Br J Nurs 28:S23-S30. 
Shimasaki M, Kanazawa Y, Sato K, Tsuchiya H, and Ueda Y (2018) Aquaporin-1 and -5 are involved in the invasion and proliferation of soft tissue sarcomas. Pathol Res Pract 214:80-88.

Sucher NJ and Carles MC (2015) A pharmacological basis of herbal medicines for epilepsy. Epilepsy Behav $\mathbf{5 2}$ (Pt B):308-318

Sui H, Han BG, Lee JK, Walian P, and Jap BK (2001) Structural basis of waterspecific transport through the AQP1 water channel. Nature 414:872-878.

Tomita Y, Palethorpe HM, Smith E, Nakhjavani M, Townsend AR, Price TJ, Yool AJ, and Hardingham JE (2019) Bumetanide-derived aquaporin 1 inhibitors, AqB013 and AqB050 inhibit tube formation of endothelial cells through induction of apoptosis and impaired migration in vitro. Int $J$ Mol Sci 20.

Törnroth-Horsefield S, Wang Y, Hedfalk K, Johanson U, Karlsson M, Tajkhorshid E, Neutze R, and Kjellbom P (2006) Structural mechanism of plant aquaporin gating. Nature 439:688-694.

Trott O and Olson AJ (2010) AutoDock Vina: improving the speed and accuracy of docking with a new scoring function, efficient optimization, and multithreading. J Comput Chem 31:455-461.

Verkman AS, Hara-Chikuma M, and Papadopoulos MC (2008) Aquaporins--new players in cancer biology. $J \mathrm{Mol} \mathrm{Med} \mathrm{(Berl)} \mathrm{86:523-529.}$

Wang Y, Fan Y, Zheng C, and Zhang X (2017) Knockdown of AQP1 inhibits growth and invasion of human ovarian cancer cells. Mol Med Rep 16:5499-5504.

Weaver CD, Shomer NH, Louis CF, and Roberts DM (1994) Nodulin 26, a nodulespecific symbiosome membrane protein from soybean, is an ion channel. $J$ Biol Chem 269:17858-17862.

Wölkart G, Schrammel A, Koyani CN, Scherübel S, Zorn-Pauly K, Malle E, Pelzmann B, Andrä M, Ortner A, and Mayer B (2017) Cardioprotective effects of 5-hydroxymethylfurfural mediated by inhibition of L-type $\mathrm{Ca}^{2+}$ currents. $\mathrm{Br}$ J Pharmacol 174:3640-3653.
Wulf E, Deboben A, Bautz FA, Faulstich H, and Wieland T (1979) Fluorescent phallotoxin, a tool for the visualization of cellular actin. Proc Natl Acad Sci USA 76:4498-4502.

Ya BL, Li HF, Wang HY, Wu F, Xin Q, Cheng HJ, Li WJ, Lin N, Ba ZH, Zhang RJ, et al. (2017) 5-HMF attenuates striatum oxidative damage via Nrf2/ARE signaling pathway following transient global cerebral ischemia. Cell Stress Chaperones 22: $55-65$.

Yanochko GM and Yool AJ (2002) Regulated cationic channel function in Xenopus oocytes expressing Drosophila big brain. J Neurosci 22:2530-2540.

Yool AJ, Brown EA, and Flynn GA (2010) Roles for novel pharmacological blockers of aquaporins in the treatment of brain oedema and cancer. Clin Exp Pharmacol Physiol 37:403-409.

Yool AJ and Campbell EM (2012) Structure, function and translational relevance of aquaporin dual water and ion channels. Mol Aspects Med 33:553-561.

Yool AJ, Stamer WD, and Regan JW (1996) Forskolin stimulation of water and cation permeability in aquaporin 1 water channels. Science 273:1216-1218.

Yoshida T, Hojo S, Sekine S, Sawada S, Okumura T, Nagata T, Shimada Y, and Tsukada K (2013) Expression of aquaporin-1 is a poor prognostic factor for stage II and III colon cancer. Mol Clin Oncol 1:953-958.

Yu J, Yool AJ, Schulten K, and Tajkhorshid E (2006) Mechanism of gating and ion conductivity of a possible tetrameric pore in aquaporin-1. Structure 14:1411-1423.

Address correspondence to: Andrea Yool, Professor of Physiology, Helen Mayo South, Level G, Frome Rd., University of Adelaide, Adelaide SA 5005 Australia. E-mail: andrea.yool@adelaide.edu.au 